\title{
Sustainable Technology Entrepreneurship and Development - the Case of Serbia
}

UDC: UDC: $330.341 .1(497.11) ; 005.342$

DOI: 10.7595/management.fon.2014.0004

SPIN' 13, Belgrade, 05-06. November 2013.

Technology entrepreneurship is oriented towards competitiveness based on strong relationships between science, new technology, learning and creating new value for the customer in the form of advanced goods and services leading to their commercialization. In this paper special focus is on two crucial issues of sustainable technology entrepreneurship: definition of the concept of technology entrepreneurship based on sustainable innovation and technology, and specific technology entrepreneurship indicators for Serbia related to vertical and horizontal technology transfer.

Keywords: Sustainable development, sustainable technology entrepreneurship, vertical and horizontal technology transfer, indicators.

\section{Introduction}

It is generally accepted, theoretically elaborated and practically tested and proved that growth and development are clearly based and dependent on new technology and innovation. Firms strategically oriented towards constant innovation and product (goods and services) and process development are the ones that survive on the market and register competitive advantages. Sustainability is the critical and key new dimension essential to modern business development and achievement of long term competitiveness.

Intensive economic growth and development is often followed by different modes of violation and endangering of the environment: resource exhaustion, water, soil and air pollution and degradation, and other. This led to the wrong conclusions that economic development necessarily brings negative environmental effects, that it is the price to be paid for the development, that it could not be realized in a different way. The efforts made in reversing this common misunderstanding are mainly oriented to directing innovation activity towards creating new sustainable, environment-friendly, green technological solutions. Operations based on green technology are enabling a simultaneously environment-friendly and profitable business activity.

There is a rising need for managing development with taking into consideration multiple factors and goals: social, economic, and environmental. Modern concepts in development management are essentially focused upon technology and innovation which are at the base of all operations and actions that man undertakes in order to fulfil the different needs and goals in nature and society. It is argued that the technology we use is the initial and determining factor of our performance and the crucial generator of risks to our environment.

The last decades of the twentieth century have witnessed a rapid ascent of the scientific discipline of technology and innovation management. This was mainly due to the rising and urgent necessity to direct, guide and manage the exponential growth of new technology towards fulfilment of social and economic goals, at all levels and in different spheres of the actions taken by mankind (Levi Jakšić, 2010). Results and breakthroughs in technology and innovation management become increasingly important, at least as important as the development of new technology per se. Today, ecological and environmental goals are especially pointed out as critical to the survival, existence, and development of mankind. The theory and practice of technology and innovation management is preferential with a crucial new dimension of sustainability incorporated in all the aspects and issues considered. The concept of sustainable technology management is based on a complex set of principles, goals, models and methods which correspond to the overall sustainable development context. (Levi Jakšić, 2011). 
The focus of theory and practice in this field is towards fundamental issues of development and implementation of sustainable technology. This means dealing with the early, initial, and all subsequent stages of guiding research and development towards scientific discoveries, new technology and innovation substantially and fundamentally leading to sustainable growth and development.

Despite the economic crisis and high degree of unemployment registered in a great number of countries, both developed and developing, the key to the resolution of these problems lies in even more intensive innovative efforts and new technological investments creating the necessary turnaround towards new sustainable opportunities for the new economic cycle of prosperity and development. The EU has proposed technological priorities in the effort to identify crucial strategic technological areas where we should concentrate creative efforts, engage material and financial assets for future development. High Expert Group delegated by the EC has pointed out five key enabling technologies, KET (European Commission, 2011) that are essential for future development:

- Advanced material technology

- Nanotechnology

- Industrial biotechnology

- Photonics

- Micro and nanoelectronics

- Advanced manufacturing systems

The above listed technologies are in the foundations and cutting across the majority of new products and services for the future. Integrated, they express multiplication and synergistic effects to social and economic development.

\section{The concept of sustainable development}

Sustainable development is a complex, multidisciplinary concept. The most widespread and generally cited definition of sustainable development was created and presented in 1987 within the Report of Brundtland. It emphasises that, in essence, sustainable development encompasses the issues of managing the overall sustainability of society, economy, organization and individuals, consistently pursuing the goal of satisfying the present needs in given circumstances, but without jeopardizing the development or creating any risks for future generations to fulfil their own needs, as well.

The concept of "green" growth has established a definite and substantial division between economic growth and environmental degradation, meaning that economic growth is not necessarily environmentally damaging, but, to the contrary, it should be and can be guided towards upgrading of the environment. The concept points out that both goals of "green" and "growth" can be accomplished bringing satisfaction of needs for present and future generations. Green growth means "further economic growth and development that ensures nature will continue to provide resources and services that our welfare depends upon." (OECD, 2011). In current practice, we are still witnessing severe violations brought to the environment by diversified operations performed under the erroneously proclaimed to be "contributions to economic growth". The understanding of economic growth should experience a transition towards the inclusion of environment goals as necessary dimensions which, if neglected, are bearing disaster and not growth. This calls for new theoretical and practical solutions with a new conceptual framework of growth and development based on a complex set of principles, models, methods for strengthening and satisfying multiple goals - social, economic, environmental, cultural, political, etc.

Sustainable development, in its essence, means working together, at a global scale and perspective, in order to create a future that will in the least possible manner exploit the resources, eliminate degradation provoked by pollution and waste accumulation, avoid any actions that provoke disturbance and disruption of the environment, build strategic, long-term dimensions for development and growth means and solutions (Levi Jakšić \& Marinković, 2012).

Eco-innovation is at the core of establishing economic growth while simultaneously keeping the environment safe. Special attention is drawn to the new business model that will bring eco-innovation to the market and enable its intensive diffusion. Based on the business model perspective, it is the new technologies and technology management issues that gain significance in generating new value with additional attributes intro- 
duced related to preservance and protection of the environment, while simultaneously realizing profitable business with innovative products (goods and services).

The identification and analysis of multiple aspects, factors and goals of sustainable development is essential. Long-term sustainability lies on developing the capacities to create decisions, solutions and act in accordance with this multi-factor perspective, oriented towards fulfilment of multiple goals.

\section{Sustainable technology entrepreneurship}

Scientific discoveries, new technology and innovation are not by themselves sufficient enough in the effort to achieve the complex sustainable development goals. The conceptual framework developed within Technology and Innovation Management discipline, intensively growing and gaining significance in the last decades, establishes the patterns, principles, models by which technological research and development are guided, directed, planned, organized and controlled within different layers of society and economy. Sustainability goals emphasize the necessity to re-examine and reassess all our practices and theoretical background, to reengineer all our processes, operations and means by which we act in the economy and society. They call for new approaches and sometimes radical changes to the already established concepts, frameworks, habits, and beliefs, meaning a complete new philosophy that is emerging in all aspects, ways and standards of life.

Te concept of technology entrepreneurship has emerged as the result of the significance of the issues of technology and innovation for production and consumption, for all economic units and actors, including firms of different size, public and private sectors, in all domains of manufacturing and services.

Technological entrepreneurship means the creation of a new business venture that generates value (welfare, business operations, employment, progress) for the actors while developing a unique, new way of combining and generating new resources, including technology, to satisfy the needs of customers and society. (Byers et al, 2011) The concept of entrepreneurship today most generally focuses upon small and medium enterprises and very broadly addresses a range of potentials defined as opportunities for new business venture or simply, new business enterprise.

Technology entrepreneurship is focused upon new technology and technological innovation as major opportunity identified in organizations of different types, where strategic management and entrepreneurial teams determine and lead projects of research and development, procurement and implementation of new technology. In other words, when any mode of vertical and/or horizontal technology transfer takes place in an organization, the complex change enforced by such projects, both incremental and radical, is recognized as technology entrepreneurship. The change is initialized by strategic management, realized through operational management and it involves all organizational segments.

In this paper special attention is given to two major issues of sustainable technology entrepreneurship:

1. clarification and precise definition of the concept of technology entrepreneurship based on sustainable technology and innovation, emphasizing the overall links within network relations and embeddedness of sustainable technology entrepreneurship deeply rooted, influenced by and dependent on complex relationships within the economy and society, and

2. analysis of special indicators of technology entrepreneurship, presented and implemented in the case of Serbia.

\subsection{Technology entrepreneurship definitions}

Technological entrepreneurship (also found under the terms techno-entrepreneurship, technical entrepreneurship, knowledge and technology entrepreneurship) encompasses in a complex way: opportunity identification and analysis, technology and innovation management, strategic management, new business models development. Different definitions of technology entrepreneurship found in literature are basically related to technology and innovation at the core of development. "Technological entrepreneurship encompasses all the activities related to the identification of potential entrepreneurial opportunities arising from 
technological developments, and the exploitation of these opportunities through the successful commercialization of innovative products (goods, services)" (Petti, 2012).

One of the definitions points to investments and projects as major determinants, "Technological entrepreneurship is an investment in a project that assembles and deploys specialized individuals and heterogeneous assets to create and capture value for the firm. What distinguishes technology entrepreneurship from other entrepreneurship types (e.g., social entrepreneurship, small business management, and self-employment) is the collaborative experimentation and production of new products, assets, and their attributes, which are intricately related to advances in scientific and technological knowledge and the firm's asset ownership rights." (Bailetti, 2012). Technology entrepreneurship exists where there is investment in new technological projects interdependent on scientific discovery and new technologies.

Some definitions emphasize risk as a significant characteristics of innovative technological projects, and it is pointed out that "technological entrepreneurship means organization, management and risk bearing of a technology based business" (Nicholas \& Armstrong, 2003; cited in Bailetti, 2012). The functions of organizing and technology management are considered as crucial along with the determination to undertake risk, meaning that technology entrepreneurship is always present when new technology is being developed and implemented in an organization.

Technological entrepreneurship, in a broad sense, deals with "transformation of technological research, developments and related investments into value: economic value in terms of returns for entrepreneurs, investors, employees and taxes for governments; and societal value in terms of growth, employability and improvement of living standards. " (Petti, 2012).

In this paper, the authors have come to the conclusion that two main determinants of technological entrepreneurship emerge within the concept broadly considered at different levels: national economy, regional, industry sector, organizational. Technological change at the organizational level is concerned with:

1. research and development activities oriented towards the development of new product (goods, services) and process technology, modification and adaptation of existing technologies (basically vertical technology transfer), and

2. procurement (purchasing) new technologies, developed by someone else, through different modes, business arrangement and transactions (i.e. horizontal technology transfer).

Strategic technology management determines the type of technology entrepreneurship in accordance with the business strategy and sustainable development goals. Technology entrepreneurship is realized by small, medium and large firms relying on internal and external factors, and diversified modes of technological entrepreneurship depend on resources, developed skills and firm competencies in concrete situations in practice.

\subsection{Technology entrepreneurship main features and significance}

The main features and the significance of sustainable technology management lie in the following:

1. Founding on sustainable technology and innovation (Mclntyre et al., 2013).

2. Technology entrepreneurship is, in a sense, a broader concept than entrepreneurship, as it encompasses a chain of activities related to both the development and implementation of technology. It expands over science and knowledge development, research and development (R\&D) where entrepreneurial direction is necessary to enhance and plan those R\&D projects and activities which possess the greatest potential to contribute to sustainable growth of the economy, region, firm and society as a whole. Technology entrepreneurship is related to vertical and horizontal technology transfers which extend entrepreneurial actions in creating new technology as well as in commercializing the technology by developing new ventures.

3. Technology entrepreneurship is, in relation to some specific issues, narrower than entrepreneurship 
due to the fact that it focuses upon technology as the opportunity to entrepreneurial venturing, thus excluding some other domains of entrepreneurial opportunity and narrowing the concept of opportunity. The main thesis is that opportunity is created by investing in technological innovation and new technology is the opportunity:

- identifying and pursuing business opportunity means also that R\&D and new technology investments are necessary as response to opportunity,

- new technology is an opportunity and technological innovation is a starting point for new ideas for business opportunity.

4. Technology entrepreneurship is realized by teams assembled to work together primarily on projects of technology development and implementation.

5. Technology entrepreneurship is embedded within the goals of modern society and it essentially contributes to sustainable development since it deals with new, green and sustainable solutions for new technology at the base of all operations. The concept of key enabling technologies (KET) directs the efforts towards those technological platforms that will lead the economy and society in the most efficient manner towards these goals.

6. Technology entrepreneurship is not related strictly to small and medium enterprises and new ventures. It is equally well implemented in new and in the existing firms as well as in firms of different sizes, including large firms. (Bailetti et al, 2012) The concept is comprehensive, it is recognized in firms of different sizes, new and old, public and private sectors, and is based upon strong network relations and strong systems of support within national economies, but also within regions and at a global level.

7. Technology entrepreneurship is analysed through different approaches, along many perspectives, from different angles. It is based on system solutions in the economy and society, it determines policy and strategies, emphasizes the role of the state, higher education, industry, and determines new business models.

\subsection{Technology entrepreneurship indicators}

Measuring entrepreneurship indicators in developed countries is a complex process that provides important information and enables analysis and comparisons. A comprehensive list of entrepreneurship indicators in the OECD report "Quality Assessment of Entrepreneurship Indicators" defines six categories of determinants: 1) The legal framework; 2) Market conditions 3) Access to finance, 4) Creating and diffusion of knowledge; 5) Entrepreneurial skills; 6) Entrepreneurial culture (OECD, 2012). Data sources in most cases are the World Bank and the OECD statistics and databases.

In case of Serbia, it is important to define entrepreneurship indicators and technology entrepreneurship indicators with valid sources in order to enable continuous monitoring and analysis. In this paper, we observe indicators classified into two groups:

1) Indicators of vertical technology transfer;

2) Indicators of horizontal technology transfer.

\subsubsection{Technology entrepreneurship indicators - vertical technology transfer}

In the field of vertical technology transfer, important macro indicators are: 1) Investments in research and development as a percentage of GDP; 2) Patent applications (residents and non-residents); and 3) Trademark applications (residents, non-residents).

Investments in R\&D is an indicator of "current and capital expenditures (both public and private) on creative work undertaken systematically to increase knowledge, including knowledge of humanity, culture, and society, and the use of knowledge for new applications. R\&D covers basic research, applied research, and experimental development" (WorldBank). Figure 1 shows the trend of the indicator R\&D investments (\% of GDP), measured for the Republic of Serbia in the period from 2003 to 2011 (Source: WorldBank). The graph 
shows that during the period 2004-2008 investments in R\&D did not exceed $0.5 \%$ of GDP, which ranked Serbia among the countries with the lowest investment in R\&D (both in the developed world and in the region). In 2008, the R\&D investment in Serbia was $0.38 \%$ of GDP, while in the EU this percentage was $1.85 \%$ (Kojic et al., 2011). According to these data, it is obvious that Serbia is far behind the EU when it comes to the intensity of investments in R\&D. However, it is encouraging to note that the value of this ratio in 2009 increased to almost $1 \%$ of GDP and has not fallen below $0.7 \%$ during the following two years (2010-2011).

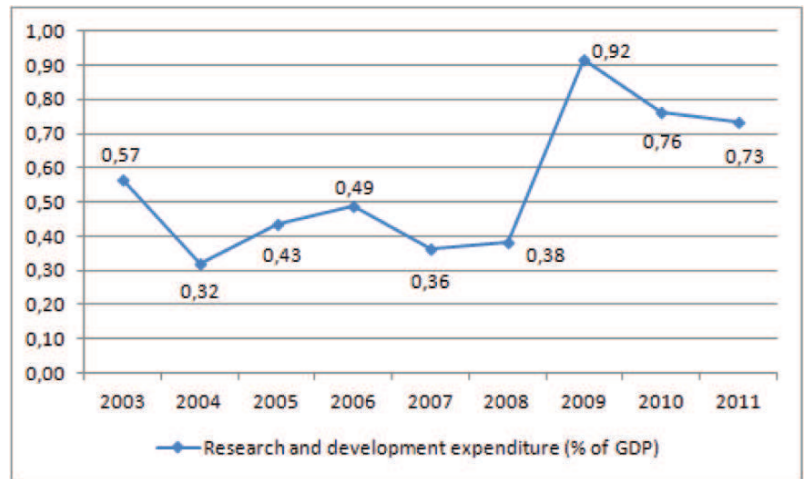

Figure 1: Trend of R\&D investments (\% of GDP) in the Republic of Serbia, period 2003-2011 (Source: WorldBank)

The second indicator - patent applications, refers to "the worldwide patent applications filed through the Patent Cooperation Treaty procedure or with a national patent office for exclusive rights for an invention - a product or process that provides a new way of doing something or offers a new technical solution to a problem" (source: WorldBank). Figure 2A shows the trends of indicators patent applications, residents and non-residents, while Figure 2B shows the trends of indicators Trademarks applications, direct residents and non-residents for the Republic of Serbia during the period 2007-2011. Trademark applications refer to "applications to register a trademark with a national or regional Intellectual Property (IP) office" (source: World Bank).

As far as patent applications in Serbia are concerned, a worrying fact is that from Figure $2 \mathrm{~A}$ we clearly see a declining trend in resident applications, from 395 applications in 2007 to only 180 applications in 2011. If we observe the region countries, in 2011 Croatia was better with 230 applications, while Albania, Bosnia and Herzegovina, Macedonia and Montenegro were worse than Serbia with 3, 43, 37 and 20 applications, respectively (source: WorldBank). Similar situation is present in Trademark applications in Serbia. From figure 2B we can see a declining trend in direct resident applications, from 1858 in 2006 to 1133 in 2011. Generally, from Figure 2 we can conclude that R\&D activity in Serbia is not fertile enough in terms of creating output in the form of protected intellectual property.
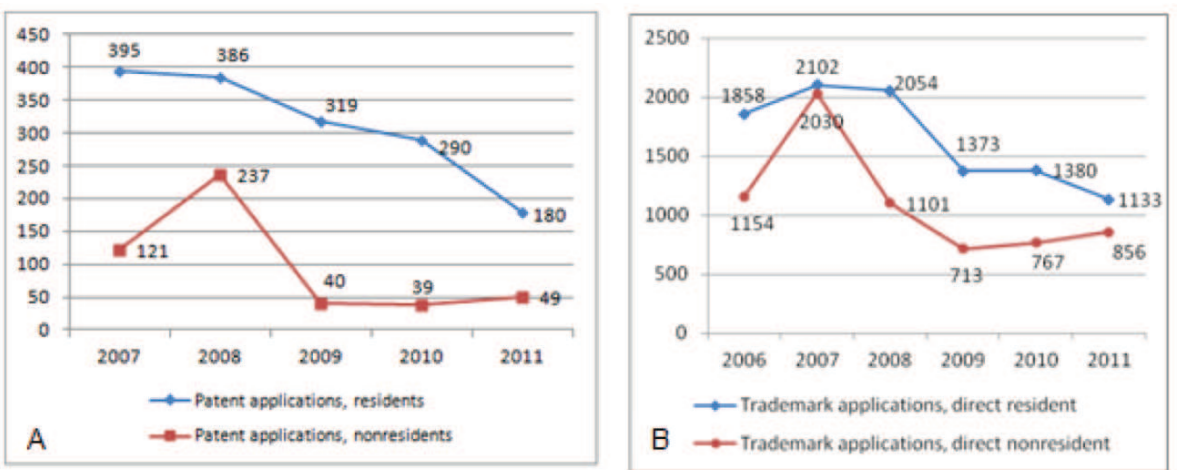

Figure 2: $2 \mathrm{~A}$ - Trend of Patent applications, residents and non-residents for the Republic of Serbia, period: 2007-2011; 2B - Trend of Trademark applications, residents and non-residents for the Republic of Serbia, period: 2007-2011

(source: WorldBank) 


\subsubsection{Technology entrepreneurship indicators - horizontal technology transfer}

In the field of horizontal technology transfer, four relevant indicators are: 1) Charges for the use of intellectual property; 2) ICT goods imports (\% of total goods imports); 3) ICT goods exports (\% of total goods exports); and 4) Total investments in equipment.

Charges for the use of intellectual property are "payments and receipts between residents and non-residents for the authorized use of proprietary rights (such as patents, trademarks, copyrights, industrial processes and designs including trade secrets, and franchises) and for the use, through licensing agreements, of produced originals or prototypes and related rights" (source: WorldBank).

Table 1 shows charges for the use of intellectual property - payment and receipts in Serbia during the period 2007-2012. Payments for the use of IP (hundreds of millions of U.S. dollars) are far above receipts for the use of IP (tens of millions). The largest payments in Serbia were in 2008 - above 196 million dollars, while the lowest payments were in 2007 and 2009 - around 143 million dollars. As far as receipts are concerned, the largest value was in 2009 - above 61 million dollars, while the lowest was in 2007 - only 10 million dollars.

Table 1: Charges for the use of intellectual property - payment and receipts in Serbia (U.S. dollars), period: 2007-2012 (Source: World Bank)

\begin{tabular}{|c|c|c|}
\hline \multicolumn{3}{|c|}{ Charges for the use of intellectual property } \\
\hline Year & Payments & Receipts \\
\hline 2007 & 143603138.4 & 10456233.7 \\
\hline 2008 & 196380003.8 & 29039521.67 \\
\hline 2009 & 143291864.2 & 61611211.98 \\
\hline 2010 & 155910993.7 & 39040235.46 \\
\hline 2011 & 183330205.4 & 56902140.75 \\
\hline 2012 & 175339875.5 & 35530709.25 \\
\hline
\end{tabular}

ICT goods imports and exports include "telecommunications, audio and video, computer and related equipment; electronic components; and other information and communication technology goods. Software is excluded" (source: WorldBank). Table 2 shows changes in ICT goods imports and exports in Serbia during the period 2007-2011. ICT goods imports in Serbia decreased over the observed period of time - from 5.73\% of total goods imports in 2007 to $4.30 \%$ in 2011 . On the other hand, ICT goods exports increased from 1.1\% of the total goods exports in 2007 to over $2 \%$ in 2008 and 2009, but then decreased to $1.42 \%$ in 2011 .

Table 2: ICT goods imports (\% of total goods imports) and ICT goods exports (\% of total goods exports) in Serbia, period: 2007-2011 (Source: World Bank)

\begin{tabular}{|l|c|c|c|c|c|}
\hline \multicolumn{1}{|c|}{ Year } & $\mathbf{2 0 0 7}$ & $\mathbf{2 0 0 8}$ & $\mathbf{2 0 0 9}$ & $\mathbf{2 0 1 0}$ & $\mathbf{2 0 1 1}$ \\
\hline $\begin{array}{l}\text { ICT goods imports } \\
\text { (\% of total goods imports) }\end{array}$ & 5.73 & 4.69 & 4.38 & 4.22 & 4.30 \\
\hline $\begin{array}{l}\text { ICT goods exports } \\
\text { (\% of total goods exports) }\end{array}$ & 1.10 & 2.04 & 2.39 & 1.63 & 1.42 \\
\hline
\end{tabular}

Table 3 shows Total investments in equipment measured for the Republic of Serbia in the period from 2004 to 2010 (Source: Statistical Yearbooks of Serbia from 2006 to 2013). Over the observed period of time, Serbia invested more money into domestic equipment. These investments increased from over 80 million RSD in 2004 to over 138 million in 2011, (for imported equipment they increased from over 62 million in 2004 to over 100 million in 2011). This resulted in the increase of the indicator Total investments in equipment - from 142 million in 2004 to 240 million in 2011 . The highest intensity of technology transfer, monitored through this indicator is observed in the period 2007-2008. 
Table 3: Total investments in equipment in Serbia (thousands RSD), period: 2004-2011 (Source: Statistical Yearbook of Serbia)

\begin{tabular}{|c|c|c|c|}
\hline \multicolumn{4}{|c|}{ Total investments in equipment } \\
\hline Year & $\begin{array}{c}\text { Domestic } \\
\text { equipment }\end{array}$ & $\begin{array}{c}\text { Imported } \\
\text { equipment }\end{array}$ & Total \\
\hline 2004 & 80281222 & 62244532 & 142525754 \\
\hline 2005 & 81733736 & 57011259 & 138744995 \\
\hline 2006 & 116015693 & 72078453 & 188094146 \\
\hline 2007 & 159917749 & 111833753 & 271751502 \\
\hline 2008 & 176793551 & 132070343 & 308863895 \\
\hline 2009 & 160396458 & 92972386 & 253368844 \\
\hline 2010 & 138435706 & 92111327 & 230547033 \\
\hline 2011 & 138713003 & 101416419 & 240129422 \\
\hline
\end{tabular}

\section{Conclusion}

Technology Entrepreneurship includes research and development activities aimed at developing new technology products (goods and services) and processes, modification and improvement of the existing ones (vertical technology transfer), as well as procurement activities, acquisition of new technologies (horizontal technology transfer) through various business arrangements and transactions. Sustainable technological entrepreneurship is based on sustainable technologies and innovation and is associated with the principles of sustainable development. Monitoring the relevant indicators of technology entrepreneurship represents an important phase in the overall process of managing the development of a society. In the case of Serbia, there is clear evidence of the lack of continuous efforts in the field of developing the most relevant set of indicators and subsequent monitoring of the technology entrepreneurship indicators. Indicators of vertical and horizontal technology transfer can provide valuable information. In this paper we analyzed Investments in research and development (\% of GDP), patent applications and trademark applications as indicators of vertical technology transfer, while charges for the use of intellectual property, ICT goods imports and exports and total investments in equipment were analyzed as indicators of horizontal technology transfer. Indicators of vertical technology transfer ranked Serbia among the countries with the lowest investment in R\&D with the declining trend of patent and trademark applications. In 2009 we noted a large increase in R\&D investments in Serbia (from $0.38 \%$ in 2008 to almost $1 \%$ of GDP in 2009), which could be an encouraging fact. But, if we take a look at the patent activity of Serbia, this well known innovation input has not yet been transformed into output, since during the period 2009-2011 we had a declining trend in patent and trademark applications in Serbia (patent applications: from 318 in 2009 to only 180 in 2011; trademark applications: from 1373 in 2009 to 1133 in 2011). The horizontal technology transfer, analysed through the above mentioned indicators, reveals that larger amounts of transfer were conducted in 2007 and 2008 compared to 2010 and 2011. Further work is needed to define technology entrepreneurship indicators through a comprehensive approach. This approach should consider the specificities of local conditions and provide valid parameters for assessment of Serbia's progress in this field.

\section{REFERENCES:}

[1] Bailetti, T. (2012). Technology Entrepreneurship: Overview, Definition, and Distinctive Aspects. Technology Innovation Management Review, February, 5-12.

[2] Bailetti, T., Bot, S., Duxbury, T., Hudson, D., McPhee, C., Muegge, S., Weiss, M., \& Wells, J., Westerlund, M. (2012). An Overview of Four Issues on Technology Entrepreneurship in the TIM Review. Technology Innovation Management Review, May 2012: Technology Entrepreneurship.

[3] Byers, T.H., Dorf, R.C., \& Nelson, A.J. (2011). Technology Ventures: From Idea to Enterprise, 3rd Ed., International Ed. McGraw Hill.

[4] European Comission (2011) High level expert group on Key enabling technologies, Final Report, June. Retreived from:http://ec.europa.eu/enterprise/sectors/ict/files/kets/hlg_report final_en.pdf

[5] Kojić, J., Levi Jakšić, M., Marinković, S., \& Petković, J. (November 2011). Research and development as an indicator of technological development performance. Paper presented at VIII Symposium of business and academics -SPIN'11 "Operations management in the function of sustainable economic development of Serbia 2011-2020", Belgrade (in Serbian).

[6] Levi Jakšić, M., \& Marinković, S. (2012). Management of sustainable development, FOS, Belgrade (in Serbian). [7] Levi Jakšić, M. (2010). Management of technology and development, Čigoja štampa, Belgrade (in Serbian). 
[8] Levi Jakšić, M. (2011). Sustainable Technology and Innovation Management, in the book Y. Tsekouras, A. Damyanov, ed., Recent Economic Crisis and Future Development Tendencies, 425-437.

[9] McIntyre, J.R., Ivanaj, S., \& Ivanaj, V. (2013). Strategies for Sustainable Technologies and Innovations, Edward Elgar, London.

[10] Nicholas, S.P., \& Armstrong, N.E. (2003). Engineering Entrepreneurship: does entrepreneurship have a role in engineering education? Antennas and Propagation Magazine, IEEE, 45(1), 134-138.

[11] OECD (2012). List of Indicators of Entrepreneurial Determinants, in entrepreneurship at a Glance 2012, OECD Publishing. http://dx.doi.org/10.1787/entrepreneur_aag-2012-27-en

[12] OECD (2011). Towards Green Growth, OECD Publishing, Paris.

[13] Petti, C. (2012). Technological Entrepreneurship in China, Edward Elgar, London.

[14] Statistical Yearbook of the Republic of Serbia (2006-2013), Statistical office of the Republic Of Serbia, available at: http://webrzs.stat.gov.rs/WebSite/

[15] WorldBank, http://data.worldbank.org/indicator (Access date: 4.3.2014.)

Receieved: November 2013. Accepted: March 2014

\section{|||||||||||||||||||||||||||||||||| soutrosenturer}

\section{Maja Levi Jaksic \\ University of Belgrade, Faculty of Organizational Sciences Levi jaksic.maja@fon.bg.ac.rs}

Maja Levi Jaksic, PhD is a full professor at the Faculty of Organizational Sciences, head of Department for Technology, Innovation and Development Management. She has been teaching as visiting professor at universities in Greece, the United Kingdom, Japan, and France and is a dual diploma Master programme leader with Middlesex University, London. Prof. Levi Jaksic has published more than 20 books and monographs, about eighty articles in journals and more than ninety papers in the proceedings of domestic and international scientific conferences. She was also a project leader and member of about twenty domestic and international scientific projects. She is member of the Editorial Board of Technovation.

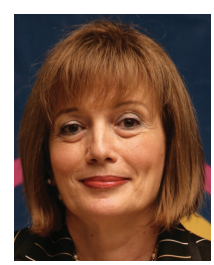

Sanja Marinkovic University of Belgrade, Faculty of Organizational Sciences marinkovic.sanja@fon.bg.ac.rs

Sanja Marinkovic, $\mathrm{PhD}$ is an assistant professor at the Faculty of Organizational Sciences, Department for Technology, Innovation and Development Management. She is the author and co-author of several books and more than 60 scientific papers. She is a lecturer and link tutor at dual award master programme International Business and Management, validated by Middlesex University, London. Her research and teaching interests lie in the fields of technology and innovation management, sustainable development and SMEs development.

\section{University of Belgrade, Faculty of Organizational Sciences rakicevic.jovana@fon.bg.ac.rs}

Jovana Rakicevic (M.Sc. Management of Development) works as a teaching assistant at the Faculty of Organizational Sciences, Department for Technology, Innovation and Development Management. She is currently enrolled in PhD studies - Information systems and management. She is the author and co-author of about twenty scientific papers. Her research and teaching area of interest includes Technology and Innovation

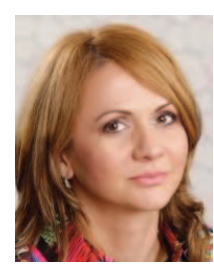
Management and SMEs Development. 